\title{
Opportunities for Surgical Research in the COVID-19 Era
}

\author{
Patrick Kyamanywa \\ Department of Surgery, Kampala International University-Western Campus, Uganda
}

Correspondence to: Prof. Patrick Kyamanywa; email: pkyamanywa0@kiu.ac.ug

Received: 07 July 2020; Revised: 14 July 2020; Accepted: 25 July 2020; Available online: 31 July 2020

Keywords: COVID-19, Surgery, Surgical research Ann Afr Surg. 2021; 18(1):1-3

DOI: http://dx.doi.org/10.4314/aas.v18i1.1

Conflicts of Interest: None
Funding: None

(C) 2021 Author. This work is licensed under the Creative Commons Attribution 4.0 International License
The World Health Organization (WHO) declared the coronavirus (COVID-19) pandemic on 11 March 2020 (1). This was followed by near total disruption of all sectors, including the health sector, that will have lasting impact. The WHO further warns that COVID-19 will be here for a long time. Without a known cure, preventive measures such as travel restrictions, social distancing and isolation have had obvious and hidden consequences, including disrupting access to and continuity of health care. Many countries suspended surgical services especially for elective cases (2), and access to surgical care has been a challenge (3). In subSaharan Africa, published guidelines to enhance the preparedness of health systems to provide essential surgical, obstetric and anesthetic services have recommended several steps aimed at reducing the risk of transmission to patients and staff, and optimizing scarce resources (3). Many surgical training programs have also been suspended. Although COVID-19 is not a surgical condition, surgery is one of the essential health services affected by the pandemic, and the surgical fraternity must adapt to the "new normal" to ensure continuity of care.

In this issue, the Annals of African Surgery presents articles on innovating and contextualizing methods (5) and materials $(6,7)$ for surgical practice in the African context. The use of locally available banana leaf dressing (BLD) for skin grafts (6) is a good example of innovative local solutions to mitigate logistical and other challenges for imported supplies presented by COVID-
19 restrictions. Although the African continent has been proportionately less affected than Europe and the Americas (4), the pandemic now places the traditional practice of medicine under the lens, and calls for innovation in the way we teach and practice surgery. Already burdened by a severe shortage of surgical workforce and weak health systems, Africa now faces worsened access to essential surgical care (9). The traditional clinical setup of surgeon-patient and surgeon-student face-to-face interactions and team practice are no longer safe and must be reassessed. Innovation, flexibility and quick adaptation of new approaches are needed for optimum safe surgical care and training, ensuring increased protection of the patient and the surgical team.

The COVID-19 virus is spread through aerosols released from an infected person's airway when talking, laughing, coughing or sneezing. The risk of transmission is higher when individuals are less than two meters apart, or when the aerosols contaminate surfaces. This is in addition to the risk of transmission by asymptomatic patients (10).

COVID-19 provides opportunity for high-quality research in several aspects of surgical care and training. Being a new disease, there are many unknowns, and time is of the essence. Its impact on surgical care and training and the predicted long-term presence and effects call for research using various designs, methods and materials to quickly address current and future challenges to surgical health systems. The African and global surgical 
fraternity needs context-specific research addressing efficiency and sustainability of interventions to ensure continuity of surgical care and training during COVID19 and future pandemics.

I propose possible research areas showing the nature of unknowns presenting as opportunities for research in surgery.

\section{Access to care}

The traditional approach to surgical care from the surgical outpatient clinics to wards and theatres has depended on person-to-person/face-to-face contact between surgeon and patient. With the new requirement for social distancing and travel restrictions in place, surgery as we know it is no longer tenable; many surgical outpatient clinics have registered decreased numbers either by design or as a consequence of the wider restrictions. This calls for research into alternative ways of delivering surgical care such as self-care, mHealth and blended care, while exploring aspects such as feasibility and cost-effectiveness. Self-care is already gaining traction as an intervention in improving patientcentered care and access to essential health, especially for sexual and reproductive health and mental health (11). Self-care in surgery has been shown to improve preoperative and postoperative performance of surgical patients $(12,13)$. The use of mobile technology (mHealth) through call centers, helplines, emergency toll-free telephone services, telemedicine and other software for consultation, patient monitoring and treatment follow-up are only growing in Africa and have not been well studied in surgery, yet they could provide a new way of increasing access and improving care (14).

\section{Ward, clinic and theatre set up and safety}

Surgical theatres are closed environments and often depend on air-conditioning. The surgical team is made up of several members, each offering a specific service for surgery to succeed. The coronavirus has been shown to spread faster in air-conditioned, closed and congested spaces, and it is now recommended to switch off airconditioning in theatre $(15,16,17)$. In addition, ventilation systems are in direct contact with the patients' airways and many procedures such as intubations, suction and endoscopy generate aerosols (18). Although the use of PPE is common in the surgical environment, the COVID-19 transmission risk may demand additional standardized operating procedures. Research is needed to inform the optimal setup and modifications necessary to ensure safety of the theatre environment.

\section{Patient triage and selection}

The provision of emergency surgical care requires intimate contact and every minute counts, posing a higher risk of infection transmission. Guidelines on how to improve surgeon and patient safety in this setting are needed, for example, guidelines on how to conduct patient triage and selection, use of PPE, disinfecting spaces, objects, and equipment, and the composition of the emergency surgical teams.

\section{The COVID-19 positive patient}

The management of the COVID-19 positive surgical patient still presents a dilemma. Various surgical societies and authorities have issued recommendations and guidelines on how to organize surgical services, prevent transmission and optimize use of the available surgical workforce and supplies $(2,4)$, but these are yet to be evaluated in the different contexts.

\section{Consent versus risks of infection}

The risk of a patient contracting infection during surgical care is ever present. The risk for COVID-19 transmission is even greater in the absence of routine screening and testing of surgical patients and teams. The current COVID19 pandemic and the ever-present high risks for patients contracting the disease during surgery (from the ventilation equipment or the surgical team) or admission to hospital might require modification of the consent to include precise mention of this risk $(19,20)$. Therefore, there may be need to research and develop guidelines on the consent process, and on handling patients who may be infected while seeking care.

\section{Training}

Surgical training requires high-volume, hands-on exposure $(21,22)$. The restrictions in place have interrupted this practice and many trainees are unable to attend to their clinical duties and learning sessions. This 
is an opportunity to review delivery of surgical training, and ensure and assess achievement of intended learning outcomes using various models such as e-learning and simulations, while maintaining safety.

Access and adherence to prevention guidelines including use of Personal Protective Equipment COVID-19 presents strict requirements for adherence to infectious disease prevention protocols beyond the routine surgical infection prevention practices. Research is needed to assess access to recommended PPE, context relevance and adherence to guidelines, to inform policy and practice in preventing disease transmission in the surgical environment.

Surgical and related research have not enjoyed as much funding as infectious diseases and other public health research, and has been referred to as the "neglected stepchild of global health" (23). However, the COVID-19 pandemic presents new funding opportunities for surgical research. As already discussed, research should address several gaps in our knowledge of safe surgical care and training in the COVID-19 era. Many governments and funding organizations are calling for proposals to address health systems strengthening, clinical management and training related to research to inform decisions and actions aimed at mitigating the effects of the COVID-19 pandemic.

We look forward to a proliferation of manuscripts from context-specific research to inform our response to the effects of COVID-19 on access, continuity and safety in surgical care and training.

\section{References}

1. World Health Organization (WHO). WHO Director-General's opening remarks at the media briefing on COVID-19, 11 March 2020. 2020a [cited 2020 July 02].

https://www.who.int/dg/speeches/detail/.

2. American College of Surgeons (ACS). COVID-19 and surgery. 2020 [cited 2020 July 02]. www.facs.org.

3. Al-Jabir A, Kerwan A, Nicola M, et al. Impact of the coronavirus (COVID-19) pandemic on surgical practice. 1. Int J Surg. 2020;79:168-179.

4. Ademuyiwa AO, Bekele A, Bakari Berhea A, et al. COVID-19 preparedness within the surgical, obstetric, and anaesthetic ecosystems in sub-Saharan Africa. East Cent Afr J Sur. 2020;25(1):1-9.
5. Valentine M, Omolade L, Omoke I. Orthopaedic day case surgery in Nigeria: a single-centre experience. Ann Afr Surg. 2020;18(1):197-203.

6. Kekisa NL, Galiwango GW, Hodges AM. A comparison between banana leaf dressing and Vaseline gauze dressing for split-thickness skin graft donor sites at a Ugandan hospital. Ann Afr Surg. 2020; 18(1):146-151.

7. Lartey S, Mohammed A, Appiagyei E, Akuffo KO. Potential for the Pentacam in screening for narrow angles in patients with chronic angle closure glaucoma. Ann Afr Surg. 2020; 18(1):183-189.

8. World Health Organization (WHO). Rolling updates on the coronavirus disease (COVID-19). 2020b. [cited 2020 July 05]. https://www.who.int/emergencies.

9. Mazingi D, Ihediwa G, Ford K, et al. Mitigating the impact of COVID-19 on children's surgery in Africa. BMJ Glob Health 2020;5:e003016.

10. World Health Organization (WHO). Transmission of SARSCoV-2: Implications for infection prevention precautions Scientific Brief. 2020 [cited 2020 July 12]. https://www.who.int.newsroom/comentaries/detail/transmissio n-of-sars-cov-2-implications-for-infection-preventionprecautions.

11. World Health Organization (WHO). WHO consolidated guideline on self-care interventions for health: sexual and reproductive health and rights Organization [online]; 2019 https://www.who.int/reproductivehealth/publications/self-careinterventions/en/

12. Adugbire BA, Aziato L. Surgical patients' perspectives on nurses education on post-operative care and follow up in Northern Ghana. BMC Nurs. 2018;17(1):29.

13. Williams B. Supporting self-care of patients following general abdominal surgery. J Clin Nurs. 2008;17(5):584-92.

14. World Health Organization (WHO). mHealth: New horizons for health through mobile technologies: second global survey on eHealth. 2011. Geneva: WHO. http://www.who.int/goe/ publications/goe_mhealth_web.pdf?ua $=1 \% 3 \mathrm{E}$

15. Lu J, Gu J, Li K, et al. COVID-19 outbreak associated with air conditioning in restaurant, Guangzhou, China, 2020. Emerg Infect Dis. 2020; 26(7):1628

16. Abdelnaser MK, Morsy M, Osman AE et al. COVID-19. An update for orthopedic surgeons. SICOT-J. 2020;6:24.

17. Ti LK, Ang LS, Foong TW et al. What we do when a COVID19 patient needs an operation: operating room preparation and guidance. Can J Anesth. 2020;6:1-3.

18. World Health Organization (WHO). Infection prevention and control during health care when novel coronavirus (nCov) infection is suspected. Interim guidance. 2020. [cited 11 July 2020. https://www.who.int/publications-detail/infectionprevention-and-control-during-health-care-when-novelcoronavirus-(ncov)-infection-is-suspected.

19. Sokol D, Dattani R. How should surgeons obtain consent during the Covid-19 pandemic? BMJ. 2020;369:m2539

20. Bhattacharya $\mathrm{N}$, Bhattacharya $\mathrm{K}$. Informed consent for surgery during COVID-19. Ind J Surg. 2020;1(3).

21. Bauer H, Honselmann KC. Minimum volume standards in surgery-Are we there yet? Visc Med. 2017;33(2):106-16.

22. Sadideen H, Alvand A, Saadeddin M, Kneebone R. Surgical experts: born or made? Int J Surg. 2013;11(9):773-8.

23. Farmer PE, Kim JY. Surgery and global health: a view from beyond the OR. World J Surg. 2008;32(4):533-6. 